\title{
Estimation of Total Carbonyl Compounds in Roasted and Dried Foods by the Tentative Method Using 1-Butanol as a Solvent
}

\author{
Riichiro Usuki ${ }^{1}$, Yuriko Shibata ${ }^{1}$, Misako Tagiri-Endo ${ }^{2}$ and Yasushi Endo ${ }^{3 *}$ \\ ${ }^{1}$ Shokei Gakuin University (4-10-1 Yurigaoka, Natori, Miyagi 981-1295, JAPAN) \\ ${ }^{2}$ Institute of Public Health and Environment, Miyagi Prefectural Government (4-7-2 Saiwai, Miyagino, Sendai 983-8666, JAPAN) \\ ${ }^{3}$ School of Bioscience and Biotechnology, Tokyo University of Technology (1404-1 Katakura, Hachioji, Tokyo 192-0982, JAPAN)
}

\begin{abstract}
Total carbonyl compounds in oils extracted from roasted and dried foods were estimated by the tentative method using 1-butanol instead of benzene as a solvent. Oils extracted from dried foods had generally showed higher carbonyl value $(\mathrm{CV})$ than those from roasted foods. The $\mathrm{CV}$ estimated by the tentative method had a good correlation with that by the conventional method in oils extracted from roasted and dried foods, although the former did not always correlate with the latter for roasted and dried foods. It was expected that the tentative method using 1-butanol could be substituted for that using benzene and be useful for evaluating the quality of oils in roasted and dried foods.
\end{abstract}

Key words: carbonyl compound, carbonyl value, dried food, lipid oxidation, roasted food

The determination of carbonyl compounds in frying oils is very important for evaluating the quality of frying fats and oils because carbonyl compounds formed during their thermal oxidation often contribute to rancid and unpleasant flavors, and reduce the nutritional value of fried foods. Therefore, the carbonyl value (2.5.4-1996) which represents the total carbonyl compounds in fats and oils has been adopted in "The Standard Methods for the Analysis of Fats, Oils and Related Materials" edited by the Japan Oil Chemists' Society ${ }^{11}$. In the standard method, carbonyl compounds present in fats and oils react with 2,4-dinitrophenylhydrazine to form the corresponding 2,4-dinitrophenylhydrazone derivatives, which are turned into quinoidals colored wine-red in alkaline solution. The total carbonyl compounds in solutions are then quantified by measuring the absorption at $440 \mathrm{~nm}$. However, the conventional method uses toxic benzene as a solvent. Therefore, we developed a method for the estimation of total carbonyl compounds in heated and frying oils by using 2-propanol ${ }^{2,3}$ and 1-butanol ${ }^{4)}$ as a solvent. In 2003, the modified method using 1-butanol was accepted as the tentative method (ten- tative 13-2003) in "The Standard Methods for the Analysis of Fats, Oils and Related Materials" by JOCS. It was also applied for evaluating the quality of deep-fried foods such as potato chips and fish oil as well as vegetable oils ${ }^{5}$. We have been also interested in the level of carbonyl compounds in non-fried foods besides deep-fried foods because some of non-fried foods are rich in oils and susceptible to oxidation. In this study, we examined whether the tentative method is available for the estimation of total carbonyl compounds in non-fried foods such as roasted and dried foods.

Roasted nuts (almond, cashew nut and peanut), broad bean and pumpkin seed, and dried fishes (sardine, anchovy and horse mackerel) and freeze-dried soybean curd were purchased from a local food market in Sendai city.

2,4-Dinitrophenylhydrazine, 2-decenal and other chemicals were purchased from Wako Pure Chemical Industries, Ltd. (Kyoto, Japan) Spectrophotometric analysis-grade 1butanol was also purchased from Wako Pure Chemical Industries, Ltd.

Oil was extracted from roasted and dried foods with

\footnotetext{
* Correspondence to: Yasushi Endo, School of Bioscience and Biotechnology, Tokyo University of Technology, 1404-1 Katakura, Hachioji, Tokyo 192-0982, JAPAN

E-mail: endo@bs.teu.ac.jp

Accepted August 21, 2008 (received for review August 1, 2008)
}

Journal of Oleo Science ISSN 1345-8957 print / ISSN 1347-3352 online

http://www.jstage.jst.go.jp/browse/jos/ 
diethyl ether after milling. The carbonyl value (CV) using 1butanol (tentative 13-2003) and benzene (2.5.4-1996) were measured according to "The Standard Methods for the Analysis of Fats, Oils and Related Materials" by JOCS ${ }^{1)}$, respectively. All data were expressed as the average for triplicate experiments.

We measured total carbonyl compounds in oil extracted from 5 roasted foods and 6 dried foods. Table 1 shows the lipid content and $\mathrm{CV}$ in roasted and dried foods. The $\mathrm{CV}$ by the tentative method was estimated as the level ( $\mu \mathrm{mol})$ of the corresponding 2-decenal per gram of oil when 2-decenal was used as a standard aldehyde. The tentative method gave 9.8-11.5 $\mu \mathrm{mol} / \mathrm{g}$ oil of CV in roasted foods, and 14.5$39.0 \mu \mathrm{mol} / \mathrm{g}$ oil of $\mathrm{CV}$ in dried foods, respectively, while the conventional method gave 3.1-7.7/g oil of CV in roasted foods, and 13.1-69.9/g oil of CV in dried foods, respectively. Oils extracted from dried foods generally had higher amounts of carbonyl compounds than those from roasted foods.

In our previous paper ${ }^{4)}$, the $\mathrm{CV}$ in frying oil estimated by the tentative method was higher than that by the conventional method. This is due to the different definition of CV. The CV is expressed as the level of the corresponding 2decenal in oil $(\mu \mathrm{mol} / \mathrm{g})$ in the tentative method, whereas it is expressed as the absorbance at $440 \mathrm{~nm}$ of oil after the reaction with 2, 4-dinitrophenylhydrazine in the conventional method. Nevertheless, there was different observation in CV between the conventional and tentative meth- ods. The CV in the tentative method in oils extracted from roasted foods was higher than that in the conventional method, while the former was lower than latter for oils extracted from dried fishes. This result was consistent with the result of fish oils previously reported ${ }^{5}$. Fish oil susceptible to oxidation sometimes showed higher CV than expected value in the conventional method. Probably the conventional method might be affected by peroxides. In the conventional method, carbonyl compounds which might be easily produced from hydroperoxides as artifacts during the process might enhance the $\mathrm{CV}^{5,6)}$. It is recommended to reduce hydroperoxides in oils over $20 \mathrm{meq} / \mathrm{kg}$ of peroxide value in the conventional method ${ }^{1)}$. Actually, the peroxide value of oils in dried fishes was much higher $(>100$ $\mathrm{meq} / \mathrm{kg})$ than that in roasted foods $(<20 \mathrm{meq} / \mathrm{kg})$. However, we observed that the tentative method was not affected by peroxides (below $40 \mathrm{meq} / \mathrm{kg}$ of peroxide value) in oil in a previous paper ${ }^{5}$.

Total carbonyl compounds in roasted and dried foods were calculated based on their lipid contents, because CV in food might be important to evaluate their oxidative deterioration. As shown in Table 1, the tentative method gave $160-537 \mu \mathrm{mol} / 100 \mathrm{~g}$ of CV in roasted foods, and 55-363 $\mu \mathrm{mol} / 100 \mathrm{~g}$ in dried foods, respectively, while the conventional method gave 70-201/100 g of CV in roasted foods, and 136-601/100 $\mathrm{g}$ in dried foods, respectively.

Almond contained the highest CV among roasted and dried foods in the tentative method, although there was no

Table 1 Lipid Content and Carbonyl Value of Roasted and Dried Foods.

\begin{tabular}{|c|c|c|c|c|c|}
\hline & \multirow[t]{2}{*}{ Lipids (\%) } & \multicolumn{2}{|l|}{$\mathrm{CV}$ in Oil } & \multicolumn{2}{|c|}{$\mathrm{CV}$ in Food ${ }^{\mathrm{c}}$} \\
\hline & & $\begin{array}{c}\text { Tentative } \\
\left(\mu \mathrm{mol}^{2} \text {-decenal/g oil }\right)^{\mathrm{a}}\end{array}$ & $\begin{array}{l}\text { Conventional } \\
(\text { ABS/g oil })^{b}\end{array}$ & $\begin{array}{c}\text { Tentative } \\
(\mu \mathrm{mol} \text { 2-decenal } / 100 \mathrm{~g} \text { food })^{\mathrm{a}}\end{array}$ & $\begin{array}{c}\text { Conventional } \\
(\mathrm{ABS} / 100 \mathrm{~g} \text { food })^{\mathrm{b}}\end{array}$ \\
\hline \multicolumn{6}{|l|}{ Roasted foods } \\
\hline Almond & 46.7 & $11.5 \pm 1.4$ & $3.5 \pm 0.3$ & $537 \pm 65$ & $163 \pm 14$ \\
\hline Casewnut & 40.9 & $9.8 \pm 1.6$ & $3.1 \pm 0.1$ & $401 \pm 65$ & $127 \pm 4$ \\
\hline Peanut & 37.5 & $10.6 \pm 0.0$ & $5.1 \pm 0.1$ & $398 \pm 0$ & $191 \pm 4$ \\
\hline Pumpkin seed & 26.1 & $11.6 \pm 0.7$ & $7.7 \pm 0.1$ & $303 \pm 18$ & $201 \pm 3$ \\
\hline Broad bean & 10.3 & $15.5 \pm 1.8$ & $6.8 \pm 0.2$ & $160 \pm 19$ & $70 \pm 2$ \\
\hline \multicolumn{6}{|l|}{ Dried foods } \\
\hline Sardine A & 6.8 & $39.0 \pm 0.0$ & $69.6 \pm 0.7$ & $265 \pm 0$ & $473 \pm 5$ \\
\hline Sardine B & 8.6 & $38.8 \pm 0.3$ & $69.9 \pm 1.3$ & $334 \pm 3$ & $601 \pm 11$ \\
\hline Anchovy & 10.1 & $28.3 \pm 0.5$ & $51.8 \pm 0.7$ & $286 \pm 5$ & $523 \pm 7$ \\
\hline Horse mackerel & 3.8 & $14.5 \pm 0.4$ & $35.8 \pm 0.3$ & $55 \pm 2$ & $136 \pm 1$ \\
\hline Soybean curd A & 23.7 & $14.5 \pm 1.4$ & $14.2 \pm 0.4$ & $344 \pm 33$ & $337 \pm 9$ \\
\hline Soybean curd B & 21.6 & $16.8 \pm 0.4$ & $13.1 \pm 0.3$ & $363 \pm 9$ & $283 \pm 6$ \\
\hline
\end{tabular}

\footnotetext{
a estimated as 2-decenal equivalent

${ }^{\mathrm{b}}$ estimated as absorbance at $440 \mathrm{~nm}$

${ }^{\mathrm{c}} \mathrm{CV}$ in food $=100 \times \mathrm{CV}$ in oil/lipid content $(\%)$
} 
significant difference in CV between roasted and dried foods. On the other hand, CV by the conventional method was higher in dried foods than roasted foods. Especially, dried sardine showed much higher CV. Dried foods were susceptible to oxidation because of low moisture, and then provided high level of hydroperoxides and their decomposition products, carbonyl compounds. This result was consistent with that obtained in oils extracted from roasted and dried foods. The higher CV in dried foods might partially include carbonyl compounds derived from hydroperoxides in them in the conventional method.

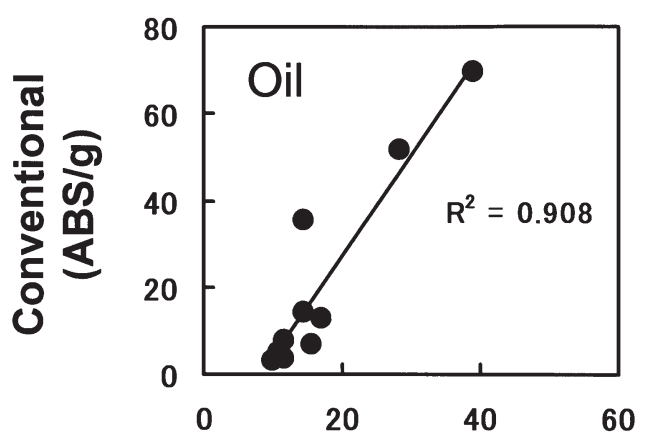

Tentative ( $\mu$ mol 2-decenal/g)

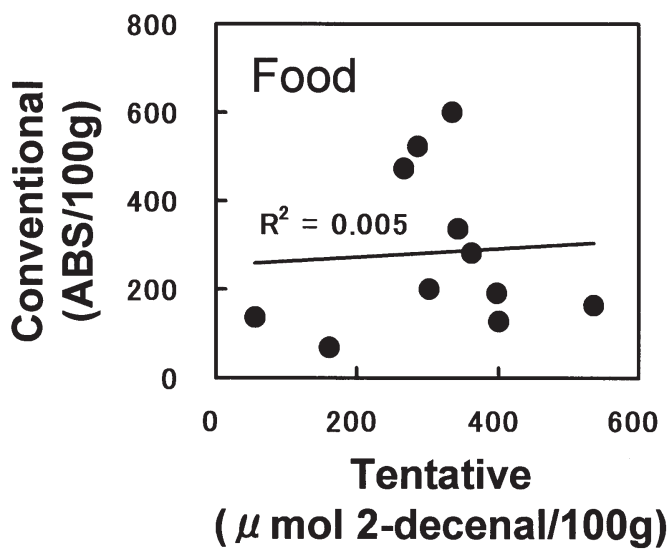

Fig. 1 Correlation Curves between Carbonyl Values of Roasted and Dried Foods and Their Oils Estimated by the Conventional and Tentative Methods.
Figure 1 shows the correlation curve in CV between the conventional and tentative methods for 11 kinds of roasted and dried foods and their oils. There was a good correlation $\left(r^{2}=0.908\right)$ for the CV (per g oil) of oils extracted from roasted and dried foods in the two different methods (Fig. 1). However, the CV (per $100 \mathrm{~g}$ of food) by the tentative method of roasted and dried foods did not always correlate with that by the conventional method. Total carbonyl compounds in roasted and dried foods may be affected by their lipid content and peroxides.

From these results, the tentative method using 1-butanol could be substituted for that using benzene and effective for evaluating the quality of oils in roasted and dried foods.

\section{References}

1. Standard Methods for the Analysis of Fats, Oils and Related Materials (Jpn. Oil Chem. Soc.ed.). (2003).

2. Endo, Y.; Li, C.-M.; Tagiri-Endo, M; Fujimoto, K. A modified method for the estimation of total carbonyl compounds in heated and frying oils using 2-propanol as a solvent. J. Am. Oil Chem. Soc. 78, 1021-1024 (2001).

3. Endo, Y.; Li, C.-M.; Fujimoto, K.; Tagiri-Endo, M.; Tooyama, K.; Usuki, R. Estimation of the deterioration of frying oil used for fishery products by the carbonyl value using 2-propanol as a solvent. Nippon Suisan Gakkaishi 69, 80-81 (2003).

4. Endo, Y.; Tominaga, M.; Tagiri-Endo, M.; Kumozaki, K.; Kouzui, H.; Shiramasa, H.; Miyakoshi, K. A modified method to estimate total carbonyl compounds in frying oils using 1-butanol as a solvent. J. Oleo Sci. 52, 353358 (2003).

5. Tagiri-Endo, M.; Usuki, R.; Eguchi, M.; Sato, Y.; Chiba, Y.; Kiyono, Y.; Sasaki, T.; Endo, Y. Estimation of deterioration in fish oil and oil-containing foods based on carbonyl values using 1-butanol as a solvent. Nippon Shokuhin Kagaku Kogaku Kaishi 54, 54-58 (2007).

6. Frankel, E.N. Lipid Oxidation, The Oily Press Ltd, Scotland, pp.55-77 (1998). 